\title{
Hyperbaric Oxygen Therapy in Non Healing Wounds in a Referral Hospital of Bangladesh
}

\author{
M RAHMAN $^{\mathrm{a}}$, MRK KHAN $^{\mathrm{b}}, \mathrm{TAHMED}^{\mathrm{c}}$, MSB ISLAM $^{\mathrm{d}}$, R NAYEEM $^{\mathrm{e}}$, MA KALAM $^{\mathrm{f}}$
}

\begin{abstract}
Summary:
Introduction: The therapeutic use of oxygen under pressure is known as hyperbaric oxygen therapy (HBOT) and has been used to assist wound healing for almost 40 years. The purpose of the present study was to see the outcome of hyperbaric oxygen therapy following its use in non healing wounds.

Methods: This prospective observational study was conducted in the Department of Plastic Surgery, Dhaka Medical College Hospital, Dhaka, from March 2016 to February 2017 for a period of 12 (twelve) months. The study was carried out on patients with non healing wounds. Patients were initially assessed with detailed history, clinical examination and investigations, and then treated with hyperbaric oxygen therapy for 90 minutes per session in 6 days a week for 25 cycles. Wound was assessed clinically, and with transcutaneous oximetry and laboratory investigations.
\end{abstract}

Results: Eighty patients were included, where 52 (65.0\%) patients had diabetic ulcer, followed by post traumatic wound (14) and venous ulcer (7). Fifty nine (73.75\%) patients had initial wound size of $<50 \mathrm{~cm}^{2}$ with mean size $14.78 \pm 12.5 \mathrm{~cm}^{2}$. Wound size reduction rate after $15 \mathrm{cycles}$

Introduction:

Oxygen is one of the most versatile and powerful agents available to the modern medical practitioner. The

a. Dr. Masroor-ur-Rahman, Assistant Registrar, Department of Plastic Surgery, Dhaka Medical College Hospital, Dhaka, Bangladesh

b. Dr. Mohammad Rabiul Karim Khan, Associate Professor (Plastic Surgery), Department of Plastic Surgery, Dhaka Medical College, Dhaka, Bangladesh

c. Dr. Tanveer Ahmed, Assistant Professor (Plastic Surgery), Department of Plastic Surgery, Dhaka Medical College, Dhaka, Bangladesh

d. Dr. Md. Salek Bin Islam, Assistant Professor (Plastic Surgery), 100 bedded Burn and Plastic Surgery Unit, Dhaka Medical College, Dhaka, Bangladesh

e. Dr. Rahatun Nayeem, Junior Consultant (Medicine), National Institute of Neuro-Sciences and Hospital, Dhaka, Bangladesh

f. Prof. Dr. Md. Abul Kalam, Professor (Plastic Surgery), Department of Plastic Surgery, Dhaka Medical College, Dhaka, Bangladesh

Address of Correspondence: Dr. Masroor-ur-Rahman, Assistant Registrar, Department of Plastic Surgery, Dhaka Medical College Hospital, Dhaka, Bangladesh. E-mail address: abir_57@yahoo.com, Mobile number: +8801711186351 .

Received: 29 August, 2018

Accepted: 27 February, 2019 of $\mathrm{HBOT}$ was $42.78 \%$, and after 25 cycles of $\mathrm{HBOT}$ it was $61.21 \%$. Among the 80 patients, 60 (75.0\%) had moderate amount of discharge before HBOT; 19 (31.67\%) \& 25 (41.67\%) reduced to small \& no discharge after 25 cycles of $\mathrm{HBOT}$ respectively. 39 (48.75\%) patients had serosanguineous discharge before HBOT, followed by 36 (45.0\%) and 5 (6.25\%) patients with purulent and serous discharge. Among the 39 patients with serosanguineous discharge, 15 (38.46\%) \& 20 (51.28\%) patients had serous \& no discharge after 25 cycles of HBOT respectively. Before starting HBOT, mean transcutaneous oximetry was 58.26 $\pm 3.84 \mathrm{mmHg}$, and it was $62.1 \pm 6.27 \mathrm{mmHg}$ and 66.92 $7.52 \mathrm{mmHg}$ after 15 and 25 cycles of HBOT respectively.

Conclusion: So it can be stated that the hyperbaric oxygen therapy is a good option in treating different non healing wounds.

Key words : Hyperbaric oxygen therapy, Non healing wounds.

(J Bangladesh Coll Phys Surg 2019; 37: 109-118)

DOI: https://doi.org/10.3329/jbcps.v37i3.41732

therapeutic use of oxygen under pressure is known as hyperbaric oxygen therapy (HBOT) and has been used to assist wound healing for almost 40 years. It is a procedure of providing $100 \%$ oxygen at higher-thanatmospheric pressure to an individual in a closed chamber. This is a treatment procedure in which the patient is placed in a chamber and breathes oxygen at higher pressure. The entire chamber is pressurized with near $100 \%$ oxygen, and the patient breathes the ambient chamber oxygen directly or it can be pressurized with air and patient breaths $100 \%$ oxygen via masks or hoods. It has positive effects on hyper-oxygenation of tissue, vasoconstriction, down regulation of inflammatory cytokines, up-regulation of growth factors, antibacterial effects, and potentiation of antibiotics. ${ }^{1}$

Most oxygen carried in the blood is bound to haemoglobin, which is about $97 \%$ saturated at standard pressure. Some oxygen, however, is carried in solution, and this portion is increased under hyperbaric conditions. Tissues at rest extract 5-6 $\mathrm{ml}$ of oxygen per decilitre of blood, assuming normal perfusion. 
Administering $100 \%$ oxygen at normobaric pressure increases the amount of oxygen dissolved in the blood to $1.5 \mathrm{ml} / \mathrm{dl}$; at 3 atmospheres, the dissolved oxygen content is approximately $6 \mathrm{ml} / \mathrm{dl}$, which is more than enough to meet resting cellular requirements without any contribution from haemoglobin. Because the oxygen is in solution, it can reach areas where red blood cells may not be able to pass and can also provide tissue oxygenation in the setting of impaired haemoglobin concentration or function. ${ }^{2}$

Hyperoxia in normal tissues causes vasoconstriction, but this is compensated by increased plasma oxygen content and microvascular blood flow. This vasoconstrictive effect reduces post-traumatic tissue oedema, which contributes to the treatment of crush injuries, compartment syndromes, and burns.

Hyperbaric oxygen therapy increases the generation of oxygen free radicals, which oxidize proteins and membrane lipids, damage DNA, and inhibit bacterial metabolic functions. It is particularly effective against anaerobes and facilitates the oxygen-dependent peroxidase system by which leukocytes kill bacteria. The unique ability of HBOT to induce neovascularization accounts for its persistence in the clinical armamentarium of chronic wound treatments. ${ }^{3}$

Normal wound healing proceeds through stages of hemostasis, removal of infectious agents, resolution of the inflammatory response, reestablishment of a connective tissue matrix, angiogenesis, and resurfacing. Chronic or non healing wounds are those which do not proceed completely through this process because of any number of local and systemic factors. For this reason, non healing wounds are often categorized as diabetic wounds, venous stasis ulcers, pressure ulcers etc. ${ }^{4}$

Wounds that fail to heal are typically hypoxic. ${ }^{5}$ Multiple components of the wound healing process are affected by oxygen concentration or gradients, which explains why hyperbaric oxygen therapy is an effective therapy to treat chronic or non healing wounds. Angiogenesis occurs in response to high oxygen concentration. ${ }^{6}$ This is a multifactorial effect of HBOT. First, fibroblast proliferation and collagen synthesis are oxygen dependent, ${ }^{7}$ and collagen is the foundational matrix for angiogenesis. In addition, HBOT stimulates growth factors involving angiogenesis and other mediators of the wound healing process. ${ }^{8}$ Hyperbaric oxygen also has been shown to have direct and indirect antimicrobial activity.

The patient can be administered systemic oxygen via two basic chambers: Multiplace and Monoplace. Both types can be used for routine wound care, treatment of most injuries, and treatment of patients who are ventilated or in critical care.

A multiplace chamber treats multiple patients at the same time, generally with a nurse or another inside observer who monitors the patients and assists with equipment manipulation or emergencies. Patients in a multiplace chamber breathe $100 \%$ oxygen via a mask or close-fitting plastic hood. ${ }^{9}$

A monoplace chamber compresses one person at a time, usually in a reclining position. The gas used to pressurize the vessel is usually $100 \%$ oxygen. Some chambers have masks available to provide an alternate breathing gas, such as air. Nurses tend to the patient from outside of the chamber and all the equipments remain outside the chamber. Only certain intravenous lines and ventilation ducts penetrate through the hull. ${ }^{9}$ The hyperbaric oxygen therapy centre of Department of Plastic Surgery of Dhaka Medical College Hospital has two Monoplace Hyperbaric System chambers.

The reasons for this study was to see the outcome of hyperbaric oxygen therapy following its use in non healing wounds, with special interest to assess the changes in wound size, to observe any change in wound discharge, to determine whether there is any change in oxygen tensions following HBOT by percutaneous measurement, and to observe the changes in antibiogram.

\section{Materials and methods:}

It was a prospective observational study, performed on the patients of Department of Plastic Surgery at Dhaka Medical College Hospital, Dhaka, Bangladesh, over a period of one year from March 2016 to February 2017. Total 80 patients with non healing wounds were 
included in the study between 18 and 65 years, presented with different non healing wounds, including diabetic foot ulcers, venous ulcers, ischaemic ulcers. We excluded patients with chronic obstructive pulmonary disorder, recent myocardial infarction, seizure disorder, claustrophobia, pregnancy, and patients that refused to give consent to take part in the study.

Different types of variables were evaluated like age, sex, aetiology, dimension of the wound, discharge from the wound, Transcutaneous oximetry (TCOM), total and differential counts of white blood cells, and wound swab findings.

After admission at the hospital, informed written consent was obtained. Then history of illness was taken and clinical examination done for initial assessment of the wound. Transcutaneous oximetry, and relevant laboratory investigations were also done. Patient was then treated with hyperbaric oxygen therapy for 90 minutes per session in 6 days a week for 25 cycles. Wound was assessed again clinically after 15 cycles and after 25 cycles, and with transcutaneous oximetry and laboratory investigations.

Ethical approval was taken prior to this study.

\section{Equipments used:}

- Two Monoplace Hyperbaric System chambers for hyperbaric oxygen therapy (Sigma 34, Perry Baromedical Corporation, USA).

- One instrument for transcutaneous oximetry (PeriFlux 6000, Perimed AB, Sweden).

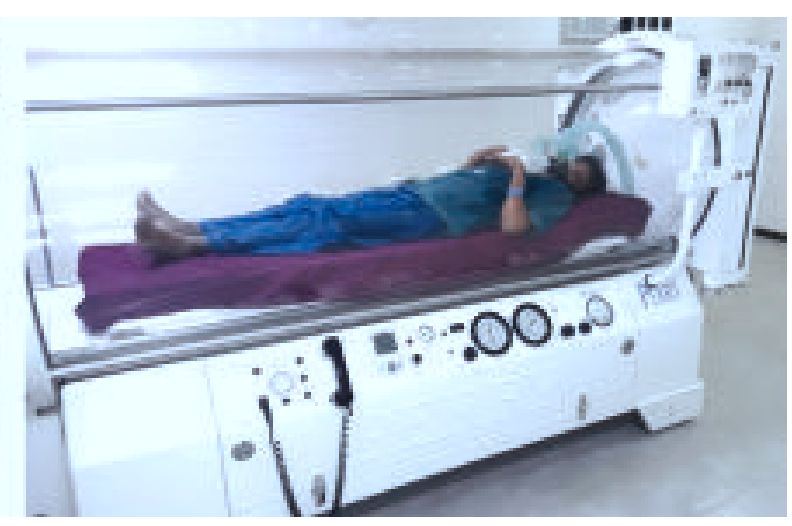

Fig.-1: Hyperbaric oxygen chambers used in the study
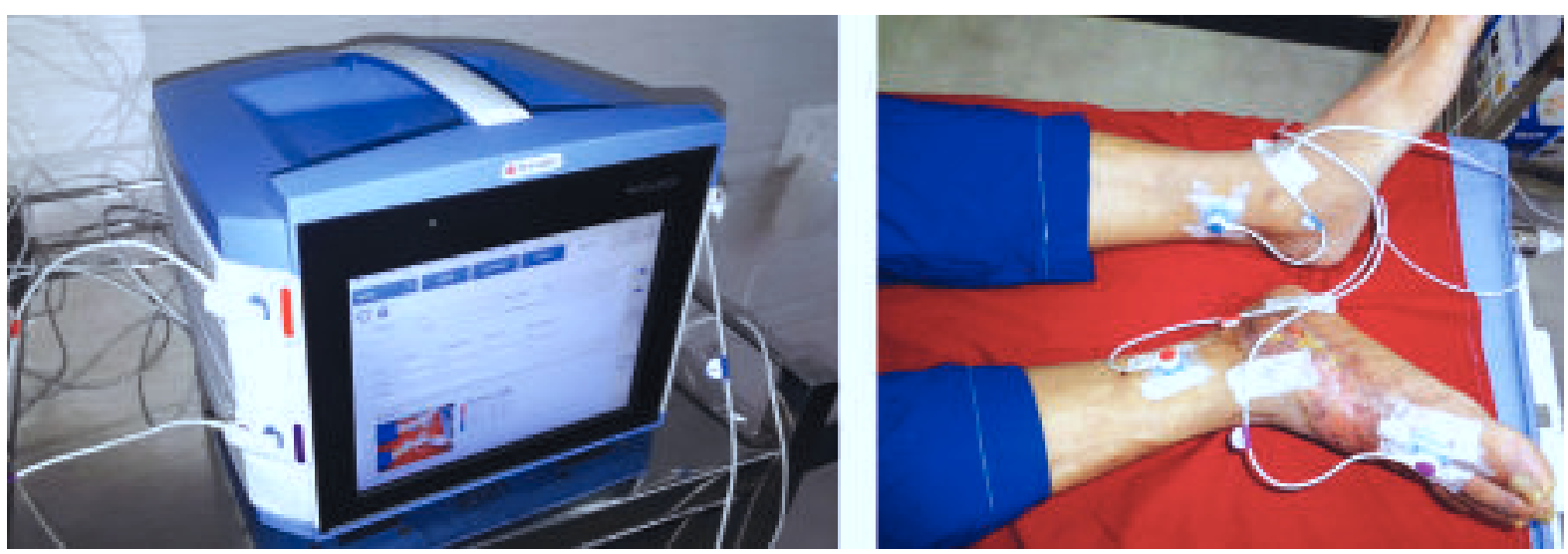

Fig.-2: Transcutaneous oximetry done in the study 


\section{Results:}

All data were compiled in a master table first. Computer based statistical analysis were carried out with appropriate techniques and systems. All data were recorded systematically in a pre-designed data collection sheet. Quantitative data were expressed as mean and standard deviation, and qualitative data were expressed as frequency distribution and percentage. Statistical analysis was performed by using windows based computer software devised with SPSS for Windows version 22, with the assistance from a statistician.

Among the patients, maximum 20 (25.0\%) patients were in age group 36-45 years followed by 17 $(21.25 \%)$ and $15(18.75 \%)$ patients were in age group $18-25$ years and $56-65$ years respectively.

Table -I

Distribution of study subjects by age $(N=80)$

\begin{tabular}{lcc} 
Age group (years) & Frequency & Percentage \\
\hline $18-25$ & 17 & 21.25 \\
$26-35$ & 14 & 17.5 \\
$36-45$ & 20 & 25.0 \\
$46-55$ & 14 & 17.5 \\
$56-65$ & 15 & 18.75 \\
\hline Total & 80 & 100.0 \\
\hline
\end{tabular}

Among the 80 patients, $63(78.75 \%)$ patients were male and $17(21.25 \%)$ were female. Majority of the patients $(52 / 80)$ had diabetic ulcer, while seven $(8.75 \%)$ patients had venous ulcer. Radionecrotic ulcer and thalassaemia were found in $4(5 \%)$ and 3 $(3.75 \%)$ patients respectively. A considerable number of patients $(14,17.5 \%)$ had post traumatic wound.

\section{Table-II}

Distribution of study subjects by aetiology $(N=80)$

\begin{tabular}{lcc} 
Aetiology & Frequency & Percentage \\
\hline Diabetic ulcer & 52 & 65.0 \\
Venous ulcer & 7 & 8.75 \\
Radionecrotic ulcer & 4 & 5.0 \\
Thalassaemia & 3 & 3.75 \\
Post traumatic & 14 & 17.5 \\
\hline Total & 80 & 100.0 \\
\hline
\end{tabular}

Among the total 80 patients, 59 (73.75\%) had initial wound size of $<50 \mathrm{~cm}^{2}$ with mean size $14.78 \pm 12.5$ $\mathrm{cm}^{2}$. After 15 cycles of HBOT, the mean size reduced to $8.46 \pm 11.64 \mathrm{~cm}^{2}$ with reduction rate of $42.78 \%$; and after 25 cycles of HBOT, the mean size reduced to $5.73 \pm 9.03 \mathrm{~cm}$ with reduction rate of $61.21 \% .17$ (21.25\%) patients had initial wound size of $50-100$ $\mathrm{cm}^{2}$ with mean size $64.71 \pm 15.23 \mathrm{~cm}^{2}$. After 15 cycles of HBOT, the mean size reduced to $55.82 \pm 11.85 \mathrm{~cm}^{2}$ with reduction rate of $13.73 \%$; and after 25 cycles of HBOT, the mean size reduced to $45.68 \pm 10.59 \mathrm{~cm}$ with reduction rate of $29.41 \%$.

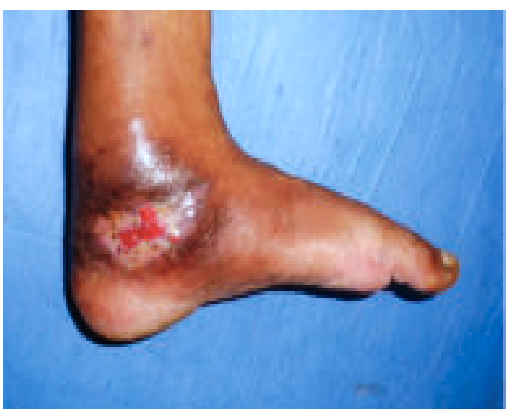

Before HBOT

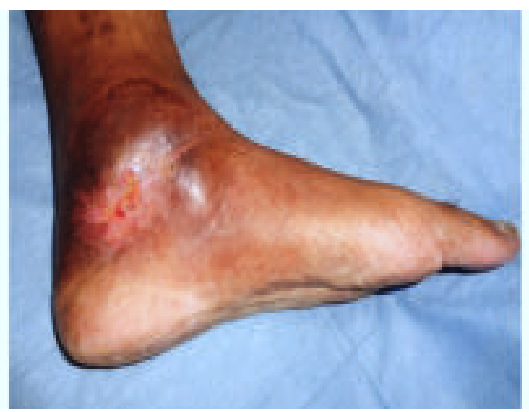

After 15 cycles of HBOT

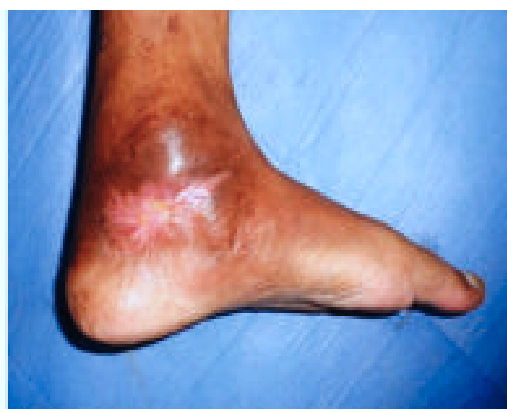

After 25 cycles of HBOT

Fig.-3: Result of use of hyperbaric oxygen therapy 
Table-III

Distribution of study subjects by dimension of wounds and reduction of wound size $(N=80)$

\begin{tabular}{|c|c|c|c|c|c|}
\hline \multirow{2}{*}{$\begin{array}{l}\text { Initial size } \\
\text { of wound }\end{array}$} & \multicolumn{2}{|c|}{ Wound before HBOT } & \multicolumn{2}{|c|}{ After 15 cycles HBOT } & \multirow[b]{2}{*}{ p-value } \\
\hline & Frequency & $\begin{array}{c}\text { Mean wound } \\
\text { size }\left(\mathrm{cm}^{2}\right) \pm \mathrm{SD}\end{array}$ & $\begin{array}{c}\text { Mean wound } \\
\text { size }\left(\mathrm{cm}^{2}\right) \pm \mathrm{SD}\end{array}$ & Reduction & \\
\hline$<50 \mathrm{~cm}^{2}$ & $59(73.75)$ & $14.78 \pm 12.5$ & $8.46 \pm 11.64$ & $42.78 \%$ & $<0.001$ \\
\hline $51-100 \mathrm{~cm}^{2}$ & $17(21.25)$ & $64.71 \pm 15.23$ & $55.82 \pm 11.85$ & $13.73 \%$ & 0.001 \\
\hline$>100 \mathrm{~cm}^{2}$ & $4(5.0)$ & $191.50 \pm 1.0$ & $164.50 \pm 23.0$ & $14.1 \%$ & 0.012 \\
\hline Initial size & \multicolumn{2}{|c|}{ Wound before HBOT } & \multicolumn{2}{|c|}{ After 25 cycles HBOT } & \\
\hline of wound & Frequency & $\begin{array}{c}\text { Mean wound } \\
\text { size }\left(\mathrm{cm}^{2}\right) \pm \mathrm{SD}\end{array}$ & $\begin{array}{c}\text { Mean wound } \\
\text { size }\left(\mathrm{cm}^{2}\right) \pm \mathrm{SD}\end{array}$ & Reduction & p-value \\
\hline$<50 \mathrm{~cm}^{2}$ & $59(73.75)$ & $14.78 \pm 12.5$ & $5.73 \pm 9.03$ & $61.21 \%$ & $<0.001$ \\
\hline $51-100 \mathrm{~cm}^{2}$ & $17(21.25)$ & $64.71 \pm 15.23$ & $45.68 \pm 10.59$ & $29.41 \%$ & $<0.001$ \\
\hline$>100 \mathrm{~cm}^{2}$ & $4(5.0)$ & $191.50 \pm 1.0$ & $141.75 \pm 16.5$ & $25.98 \%$ & 0.011 \\
\hline
\end{tabular}

Among the 80 patients, $60(75.0 \%)$ had moderate amount of discharge, and $20(25.0 \%)$ patients had profuse discharge. Among the 20 patients with profuse discharge, $17(85.0 \%)$ reduced to moderate amount of discharge after 15 cycles of HBOT, and $12(60.0 \%)$ \& $8(40.0 \%)$ patients reduced to moderate \& small amount of discharge after 25 cycles of HBOT respectively. Among the 60 patients with moderate discharge, $40(66.67 \%)$ reduced to small amount of discharge after 15 cycles of HBOT, and $19(31.67 \%)$ \& $25(41.67 \%)$ patients reduced to small \& no discharge after 25 cycles of HBOT respectively.

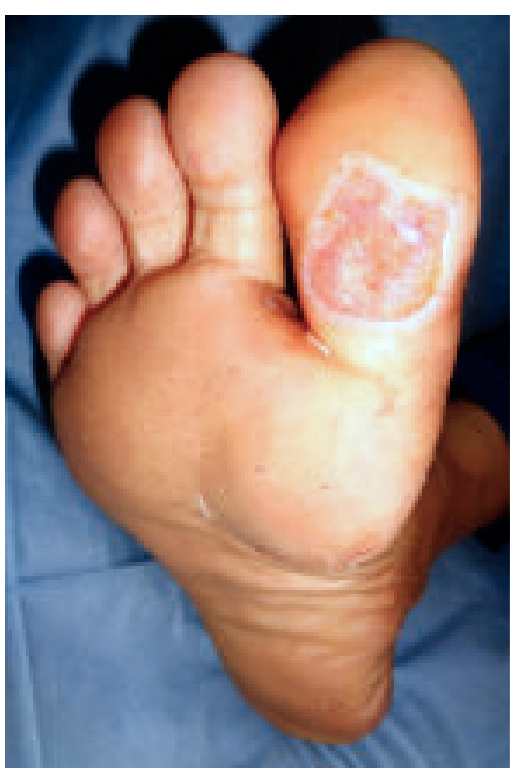

Before HBOT

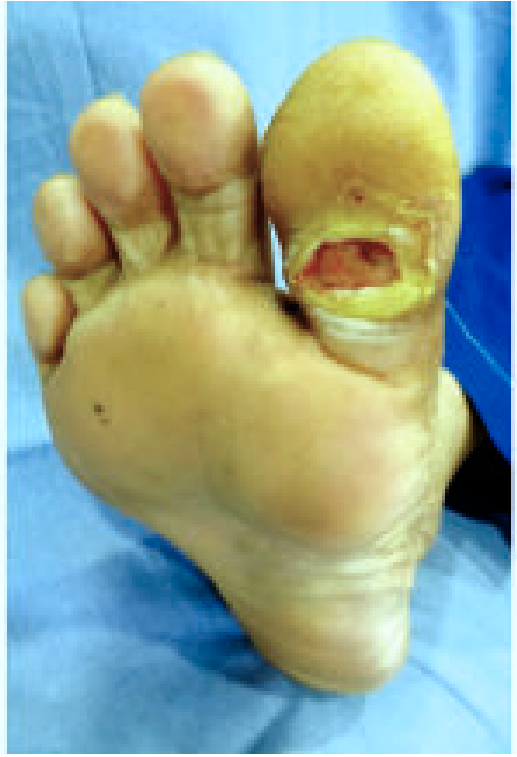

After 15 cycles of HBOT

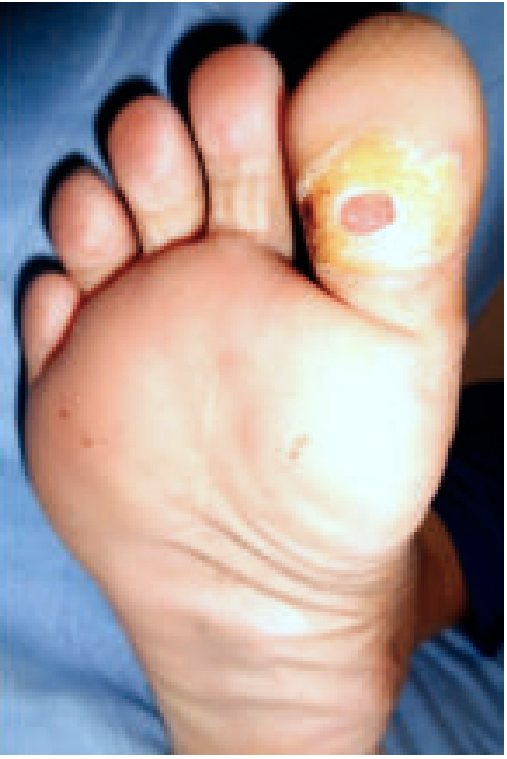

After 25 cycles of HBOT

Fig.-4: Result of use of hyperbaric oxygen therapy 
Table-IV

Distribution of study subjects by change in amount of discharge after HBOT $(N=80)$

\begin{tabular}{|c|c|c|c|c|}
\hline \multirow{3}{*}{ Amount } & \multicolumn{4}{|c|}{ Profuse discharge before HBOT $\left(\mathrm{n}_{\mathrm{pr}}=20\right)$} \\
\hline & \multicolumn{2}{|c|}{ After 15 cycles HBOT } & \multicolumn{2}{|c|}{ After 25 cycles HBOT } \\
\hline & Frequency & Percentage $(\%)$ & Frequency & Percentage $(\%)$ \\
\hline$\overline{\text { Profuse }}$ & 3 & 15.0 & 0 & 0.0 \\
\hline Moderate & 17 & 85.0 & 12 & 60.0 \\
\hline Small & 0 & 0.0 & 8 & 40.0 \\
\hline Nil & 0 & 0.0 & 0 & 0.0 \\
\hline \multirow[t]{2}{*}{ Total } & 20 & 100.0 & 20 & 100.0 \\
\hline & \multicolumn{4}{|c|}{ Moderate discharge before HBOT $\left(\mathrm{n}_{\mathrm{mo}}=60\right)$} \\
\hline \multirow[t]{2}{*}{ Amount } & \multicolumn{2}{|c|}{ After 15 cycles HBOT } & \multicolumn{2}{|c|}{ After 25 cycles HBOT } \\
\hline & Frequency & Percentage $(\%)$ & Frequency & Percentage $(\%)$ \\
\hline Profuse & 0 & 0.0 & 0 & 0.0 \\
\hline Moderate & 20 & 33.33 & 16 & 26.67 \\
\hline Small & 40 & 66.67 & 19 & 31.67 \\
\hline Nil & 0 & 0.0 & 25 & 41.67 \\
\hline Total & 60 & 100.0 & 60 & 100.0 \\
\hline
\end{tabular}

Among the total 80 patients, $39(48.75 \%)$ patients had serosanguineous discharge, followed by $36(45.0 \%)$ and $5(6.25 \%)$ patients with purulent and serous discharge respectively. Among the 36 patients with purulent discharge, 24 (66.67\%) \& 4 (11.11\%) had serosanguineous \& serous discharge after 15 cycles of HBOT respectively, and 21 (58.33\%), 7 (19.44\%) \& $4(11.11 \%)$ patients had serosanguineous, serous \& no discharge after 25 cycles of HBOT respectively. Among the 39 patients with serosanguineous discharge, $32(82.05 \%)$ had serous discharge after 15 cycles of HBOT, and $15(38.46 \%) \& 20(51.28 \%)$ patients had serous \& no discharge after 25 cycles of HBOT respectively. Among the 5 patients with serous discharge, $2(40.0 \%)$ patients had no discharge after 25 cycles of HBOT.

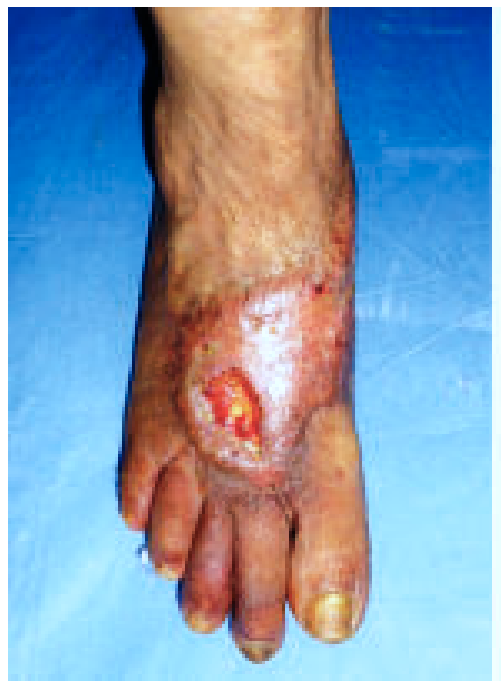

Before HBOT

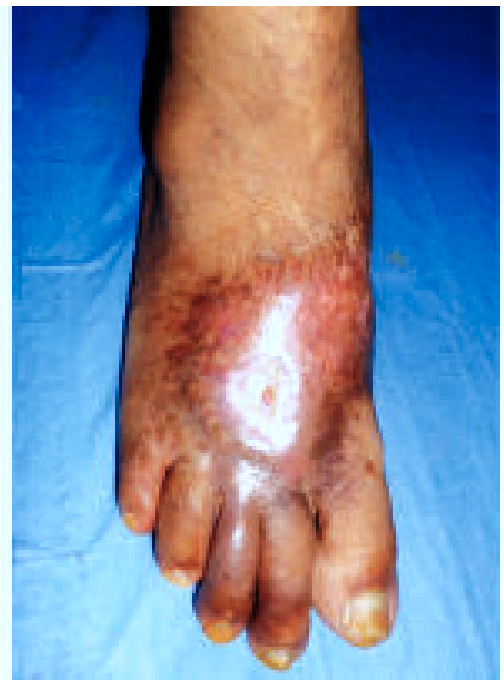

After 15 cycles of HBOT

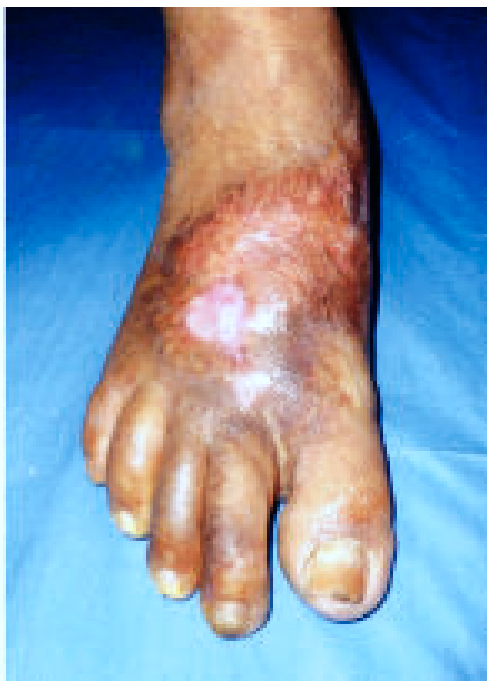

After 25 cycles of HBOT

Fig.-5: Result of use of hyperbaric oxygen therapy 


\section{Table-V}

Distribution of study subjects by change in type of discharge after HBOT $(N=80)$

Purulent discharge before HBOT $\left(\mathrm{n}_{\mathrm{pu}}=36\right)$

\begin{tabular}{|c|c|c|c|c|}
\hline \multirow[t]{2}{*}{ Amount } & \multicolumn{2}{|c|}{ After 15 cycles HBOT } & \multicolumn{2}{|c|}{ After 25 cycles HBOT } \\
\hline & Frequency & Percentage $(\%)$ & Frequency & Percentage $(\%)$ \\
\hline Purulent & 8 & 22.22 & 4 & 11.11 \\
\hline Serosanguineous & 24 & 66.67 & 21 & 58.33 \\
\hline Serous & 4 & 11.11 & 7 & 19.44 \\
\hline Nil & 0 & 0.0 & 4 & 11.11 \\
\hline \multirow[t]{2}{*}{ Total } & 36 & 100.0 & 36 & 100.0 \\
\hline & \multicolumn{4}{|c|}{ Serosanguineous discharge before HBOT $\left(n_{\mathrm{ss}}=39\right)$} \\
\hline \multirow[t]{2}{*}{ Amount } & \multicolumn{2}{|c|}{ After 15 cycles HBOT } & \multicolumn{2}{|c|}{ After 25 cycles HBOT } \\
\hline & Frequency & Percentage $(\%)$ & Frequency & Percentage $(\%)$ \\
\hline Purulent & 0 & 0.0 & 0 & 0.0 \\
\hline Serosanguineous & 7 & 17.95 & 4 & 10.26 \\
\hline Serous & 32 & 82.05 & 15 & 38.46 \\
\hline Nil & 0 & 0.0 & 20 & 51.28 \\
\hline Total & 39 & 100.0 & 39 & 100.0 \\
\hline
\end{tabular}

\begin{tabular}{lccccc}
\hline \multirow{2}{*}{ Amount } & \multicolumn{4}{c}{ Serous discharge before HBOT $\left(\mathrm{n}_{\mathrm{se}}=5\right)$} \\
\cline { 2 - 3 } \cline { 6 - 7 } & \multicolumn{2}{c}{ After 15 cycles HBOT } & & \multicolumn{2}{c}{ After 25 cycles HBOT } \\
\cline { 2 - 3 } \cline { 5 - 6 } & Frequency & Percentage (\%) & & Frequency & Percentage (\%) \\
\hline Purulent & 0 & 0.0 & & 0 & 0.0 \\
Serosanguineous & 0 & 0.0 & & 0 & 0.0 \\
Serous & 5 & 100.0 & & 3 & 60.0 \\
Nil & 0 & 0.0 & & 2 & 40.0 \\
\hline Total & 5 & 100.0 & & 5 & 100.0 \\
\hline
\end{tabular}

Before starting HBOT, mean transcutaneous oximetry (TCOM) was $58.26 \pm 3.84 \mathrm{mmHg}$, and it was $62.1 \pm 6.27$ $\mathrm{mmHg}$ and $66.92 \pm 7.52 \mathrm{mmHg}$ after 15 and 25 cycles of HBOT respectively.

Table-VI

Distribution of study subjects by transcutaneous oximetry (TCOM) $(N=80)$

\begin{tabular}{lcc} 
& Mean TCOM $(\mathrm{mmHg}) \pm \mathrm{SD}$ & p-value \\
\hline Before HBOT & $58.26 \pm 3.84$ & $<0.001$ \\
After 15 cycles HBOT & $62.10 \pm 6.27$ & \\
Before HBOT & $58.26 \pm 3.84$ & $<0.001$ \\
After 25 cycles HBOT & $66.92 \pm 7.52$ & \\
\hline
\end{tabular}

Before starting HBOT, mean WBC count was 10681.25 $\pm 3066.07 / \mathrm{cmm}$, and it was $9946.25 \pm 2589.46 / \mathrm{cmm}$ and $9322.5 \pm 2313.09 / \mathrm{cmm}$ after 15 and 25 cycles of HBOT respectively. Among the 80 patients, all 80
(100.0\%) had presence of infection by different microorganisms before starting HBOT, but it was reduced to $56(70.0 \%)$ patients after 15 cycles of HBOT and 38 (47.5\%) patients after 25 cycles of HBOT. 


\section{Table-VII}

Distribution of study subjects by presence of infection according to antibiogram $(N=80)$

\begin{tabular}{lcccccccc}
\multirow{2}{*}{ Infection } & \multicolumn{2}{c}{ Before HBOT } & & \multicolumn{2}{c}{ After 15 cycles HBOT } & & \multicolumn{2}{c}{ After 25 cycles HBOT } \\
\cline { 2 - 3 } & Frequency & Percentage (\%) & & Frequency & Percentage (\%) & & Frequency & Percentage (\%) \\
\hline Present & 80 & 100.0 & & 56 & 70.0 & & 38 & 47.5 \\
Absent & 0 & 0.0 & & 24 & 30.0 & & 42 & 52.5 \\
\hline Total & 80 & 100.0 & 80 & 100.0 & 80 & 100.0 \\
\hline
\end{tabular}

\section{Discussion:}

In the study, the distribution of subjects by aetiology of wounds was recorded. Among all patients, 52 $(65.0 \%)$ patients had diabetic ulcer, followed by 14 $(17.5 \%)$ and $7(8.75 \%)$ patients had post traumatic wound and venous ulcer respectively.

The distribution of study subjects by dimension of wounds was recorded. Among the total 80 patients, 59 (73.75\%) had initial wound size of $<50 \mathrm{~cm}^{2}$ with mean size $14.78 \pm 12.5 \mathrm{~cm}^{2}$. After 15 cycles of HBOT, the mean size reduced to $8.46 \pm 11.64 \mathrm{~cm}^{2}$ with reduction rate of $42.78 \%$; and after 25 cycles of HBOT, the mean size reduced to $5.73 \pm 9.03 \mathrm{~cm}$ with reduction rate of $61.21 \% .17(21.25 \%)$ patients had initial wound size of $50-100 \mathrm{~cm}^{2}$ with mean size $64.71 \pm 15.23 \mathrm{~cm}^{2}$. After 15 cycles of HBOT, the mean size reduced to $55.82 \pm 11.85 \mathrm{~cm}^{2}$ with reduction rate of $13.73 \%$; and after 25 cycles of HBOT, the mean size reduced to $45.68 \pm 10.59 \mathrm{~cm}$ with reduction rate of $29.41 \%$. Hammarlund et al showed that the mean decrease of the wound areas at weeks 4 and 6 in the oxygen group were $22 \%(\mathrm{SD} \pm 13)$, and $35.7 \%(\mathrm{SD} \pm 17)$ respectively, and in the air group, 3.7\% $(\mathrm{SD} \pm 11)$, and $2.7 \%(\mathrm{SD} \pm$ 11) respectively. ${ }^{10}$ So the present study reports similar results. Londahl et al also showed that complete healing of the index ulcer was achieved in $52 \%$ of the patients in the HBOT group and $29 \%$ in the placebo group at 1 year follow up. ${ }^{11}$

The distribution of study subjects by amount of discharge before and after administration of HBOT was recorded. Here profuse discharge was mentioned where wound tissues were bathed in fluid, drainage freely expressed, may or may not be evenly distributed in wound and drainage involves $>75 \%$ of dressing; moderate discharge mentioned where wound tissues were saturated, drainage may or may not be evenly distributed in wound and drainage involves $>25 \%$ to $<75 \%$ dressing; and small amount of discharge mentioned where wound tissues were wet, moisture evenly distributed in wound and drainage involves $<25 \%$ dressing. ${ }^{12}$ Among the 80 patients, 60 (75.0\%) had moderate amount of discharge before HBOT, and 20 $(25.0 \%)$ patients had profuse discharge. Among the 20 patients with profuse discharge, $17(85.0 \%)$ reduced to moderate amount of discharge after 15 cycles of HBOT, and $12(60.0 \%) \& 8(40.0 \%)$ patients reduced to moderate \& small amount of discharge after 25 cycles of HBOT respectively. Among the 60 patients with moderate discharge, $40(66.67 \%)$ reduced to small amount of discharge after 15 cycles of HBOT, and 19 (31.67\%) \& 25 (41.67\%) patients reduced to small \& no discharge after 25 cycles of HBOT respectively.

The distribution of study subjects by type of discharge before and after administration of HBOT was recorded. Purulent discharge was mentioned to describe thin or thick opaque discharge, tan to yellow in colour; serosanguineous was thin watery discharge, red to pink in colour; and serous was thin watery clear discharge. ${ }^{12}$ Among the total 80 patients, 39 (48.75\%) patients had serosanguineous discharge before HBOT, followed by $36(45.0 \%)$ and $5(6.25 \%)$ patients with purulent and serous discharge respectively. Among the 36 patients with purulent discharge, 24 (66.67\%) \& 4 (11.11\%) had serosanguineous \& serous discharge after 15 cycles of HBOT respectively, and 21 (58.33\%), 7 (19.44\%) \& 4 (11.11\%) patients had serosanguineous, serous \& no discharge after 25 cycles of HBOT respectively. Among the 39 patients with serosanguineous discharge, $32(82.05 \%)$ had serous discharge after 15 cycles of HBOT, and 15 (38.46\%) \& $20(51.28 \%)$ patients had serous \& no discharge after 25 cycles of HBOT respectively. Among the 5 patients with serous discharge, $2(40.0 \%)$ patients had no discharge after 25 cycles of HBOT. 
The distribution of study subjects by transcutaneous oximetry (TCOM) was recorded. Transcutaneous oximetry provides a simple, reliable noninvasive diagnostic technique for the objective assessment of wound perfusion and oxygenation. ${ }^{13}$ It can be used for serial assessment of tissue perfusion in the vicinity of the foot ulcer. Transcutaneous oximetry may be used in the assessment of healing potential and patient selection for HBOT. ${ }^{14}$ Before starting HBOT, mean TCOM was $58.26 \pm 3.84 \mathrm{mmHg}$, and it was $62.1 \pm$ $6.27 \mathrm{mmHg}$ and $66.92 \pm 7.52 \mathrm{mmHg}$ after 15 and 25 cycles of HBOT respectively. The difference between the results was statistically significant $(p<0.001)$. So in the present study it showed TCOM increase of 8.66 $\mathrm{mmHg}$ after 25 cycles of HBOT, which is similar to Faglia et al who showed that the transcutaneous oxygen tension measured on the dorsum of the foot significantly increased in subjects treated with hyperbaric oxygen therapy: $14.0 \pm 11.8 \mathrm{mmHg}$ in treated group and $5.0 \pm 5.4 \mathrm{mmHg}$ in non-treated group. ${ }^{15}$

The distribution of patients by presence of infection according to antibiogram is recorded. Among the 80 patients, all $80(100.0 \%)$ had presence of infection by different micro-organisms before starting HBOT, but it was reduced to $56(70.0 \%)$ patients after 15 cycles of HBOT and $38(47.5 \%)$ patients after 25 cycles of HBOT. Doctor et al showed the control of infection and wound healing was achieved with the help of hyperbaric oxygen therapy. The control of infection spread was quicker. Positive cultures decreased from initial 19 to 3 in study group as against from 16 to 12 in the control group. ${ }^{16}$

\section{Limitation of the study}

The study was conducted in a single centre in Dhaka city which may not be representative for the whole population. The sample size was small in the present study, which compromises the generalizibility of the study. If the study could have been done for a longer period of time, more significant data and results could have been yielded.

\section{Conclusion:}

The standard of care for treating non healing wounds includes the use of debridement, antibacterials, dressings, administration of antibiotics to control infection, adequate nutrition, maintenance of optimal blood glucose levels, and pressure relief in the areas that are most subject to weight bearing. But when these measures are not enough to combat the difficult situation, administration of hyperbaric oxygen therapy is a very reliable option.

The present study revealed many important aspects of administration of hyperbaric oxygen therapy in non healing wounds. Wound size was reduced significantly after administration of HBOT. Amount of discharge from the wound was reduced. Wound perfusion and oxygenation was increased, which was evident in transcutaneous oximetry; and the presence of infection by different micro-organisms was reduced. So hyperbaric oxygen therapy has proven to be effective for different types of non healing wounds where other traditional treatment modalities are being ineffective.

\section{Recommendation:}

A large scale multi-centred study is recommended for more in-depth analysis of the role of hyperbaric oxygen therapy in non healing complex wound management in Bangladesh.

\section{References:}

1. Ahmed T, Kalam MA, Khondoker MS, Awwal R, Imam H. Hyperbaric Oxygen Therapy: Role in Medical Practice. Bangladesh Journal of Plastic Surgery 2014; 5(2): 50-61.

2. Feldmeier J. Hyperbaric Oxygen 2003: Indications and ResultsThe Hyperbaric Oxygen Therapy Committee Report. Kensington, Maryland: Undersea and Hyperbaric Medical Society, Inc.; 2003.

3. Fife CE, Hopf H. Discussion. Hyperbaric oxygen: its mechanisms and efficacy. Plast Reconstr Surg 2011; 127(Suppl 1): 142S-143S.

4. Latham E. Hyperbaric Oxygen Therapy. (July 2016). http:// emedicine.staging.medscape.com/article/1464149

5. Hunt TK, Twomey P, Zederfeldt B, et al. Respiratory gas tensions and $\mathrm{pH}$ in healing wounds. Am J Surg 1967; 114(2): 302-307.

6. Knighton DR, Silver IA, Hunt TK. Regulation of wound-healing angiogenesis - effect of oxygen gradients and inspired oxygen concentration. Surgery 1981; 90(2): 262-270.

7. Hunt TK, Pai MP. The effect of varying ambient oxygen tensions on wound metabolism and collagen synthesis. Surg Gynecol Obstet 1972; 135(4): 561-567.

8. Sheikh AY, Gibson JJ, Rollins MD, et al. Effect of hyperoxia on vascular endothelial growth factor levels in a wound model. Arch Surg 2000; 135(11): 1293-1297.

9. Kindwall E, Whelan H. Hyperbaric Medicine Practice. 2nd ed. Flagstaff, AZ: Best Publishing Company; 2004.

10. Hammarlund C, Sundberg T. Hyperbaric oxygen reduced size of chronic leg ulcers: A randomized double-blind study. Plast Reconstr Surg 1994; 93: 829-833. 
11. Londahl M, Katzman P, Nilsson A, et al. A prospective study: Hyperbaric oxygen therapy in diabetics with chronic foot ulcers. J Wound Care 2006; 15: 457-469.

12. Bates-Jensen BM, Vredevoe DL, Brecht M-L. Validity and reliability of the pressure sore status tool. Decubitus 1992; 5(6): 20-28.

13. Matos LA, Nun ez AA. Enhancement of healing in selected problem wounds. In: Kindwall E, editor. Hyperbaric medicine practice, 1994. Flagstaff, AZ: Best Publishing Co., 1994: 589-612.

14. Niinikoski J. Hyperbaric oxygen therapy of diabetic foot ulcers, transcutaneous oxymetry in clinical decision-making. Wound Repair Regen 2003; 11:458-461.
15. Faglia E, Favales F, Aldeghi A, Calia P, Quarantiello A, Oriani G, et al. Adjunctive systemic hyperbaric oxygen therapy in treatment of severe prevalently ischemic diabetic foot ulcer. A randomized study. Diabetes Care 1996; 19(12): 1338-1343.

16. Doctor N, Pandya S, Supe A. Hyperbaric oxygen therapy in diabetic foot. J Postgrad Med 1992; 38(3): 112-114.

17. O'Reilly D, Linden R, Fedorko L, et al. A prospective, doubleblind, randomized, controlled clinical trial comparing standard wound care with adjunctive hyperbaric oxygen therapy (HBOT) to standard wound care only for the treatment of chronic, nonhealing ulcers of the lower limb in patients with diabetes mellitus: A study protocol. Trials 2011; 12: 69. 